\title{
Estimation of Human Drug Clearance Using Multiexponential Techniques
}

\author{
Kosalaram Goteti, PhD, Patrick J. Brassil, PhD, Steven S. Good, MS, \\ and C. Edwin Garner, PhD
}

A multiexponential allometry (MA) method was developed to predict human drug clearance from preclinical data. Separate data sets containing clearances from human and preclinical species were chosen for the study. Human clearance was estimated using the MA technique according to the equation: $\mathrm{CL}=\mathrm{aBW}^{\mathrm{b}}+\mathrm{cBW}^{\mathrm{d}}$, where CL is clearance in milliliters/minute, and a, b, c, and d are constants derived from preclinical pharmacokinetic data. Simple allometry ( $S A$ ) gave the poorest prediction using any data set, and the percentage outliers remained larger than MA or monkey liver blood flow within 1.5-, 2-, and 3-fold error. Analysis of compounds common to both data sets suggested that MA could accurately predict human clearances within approximately $10 \%$ of 3 -fold error. The analysis also showed that monkey is an important species for scaling, and MA is a better predictor of human clearance when the slope of $S A$ is $>0.7$.

Keywords: Allometry; clearance; human pharmacokinetics; monkey liver blood flow (MLBF)

Journal of Clinical Pharmacology, $X X X X ; X X: X X-X X$ (C) 2008 the American College of Clinical Pharmacology
C learance is an important pharmacokinetic parameter that determines the rate at which a drug is eliminated from an organism. One of the most important tasks in drug discovery and development is the prediction of human drug clearance, so that a new chemical entity can move from preclinical to clinical development, and it helps increase confidence on new chemical entity selection for development. To predict human pharmacokinetic profiles, human clearance is very often estimated from pharmacokinetic data of preclinical species. ${ }^{1,2}$

Simple allometric (SA) scaling is a technique in which the log transform of clearance from preclinical species is correlated with body weight to predict clearance in humans. ${ }^{3,4}$ Because of the simplicity of the technique, it is one of the most popular methods for predicting human clearance from clearances

From Infection and Cancer Discovery, AstraZeneca R\&D Boston, Waltham, MA 02451 . Submitted for publication February 28, 2008; revised version accepted May 5, 2008. Address for correspondence: Kosalaram Goteti, PhD, Department of Drug Metabolism and Pharmacokinetics, AstraZeneca R\&D Boston, 35 Gatehouse Drive, Waltham, MA 02451; e-mail: Kosalaram.Goteti@astrazeneca.com.

DOI: $10.1177 / 0091270008320369$ measured in preclinical species. However, SA has not been entirely successful in the estimation of human clearance, and the poor prediction of human drug clearance by SA for drugs with certain exponents was first identified by Mahmood and Balian. ${ }^{5}$ There have been several attempts by various groups to improve human clearance predictions using various techniques. Some of these include 2- or 3species allometry, ${ }^{6}$ rule of exponents, ${ }^{5}$ liver blood flow methods, ${ }^{7}$ and in vitro techniques. ${ }^{8}$ The monkey liver blood flow (MLBF) technique, which is based on the ratio of human and monkey hepatic blood flow and monkey clearance, was found to be one of the best methods to predict human clearance compared to SA. ${ }^{7}$ Each of these techniques mentioned has its own merits and demerits, and some of them have had only partial success in predicting human clearance. There still remains a need to improve the accuracy of human clearance estimates because of the human safety risk and tremendous financial costs that are associated with failed clinical trials. The goal of this article was to improve the estimation of human clearance by introducing a novel multiexponential allometric (MA) approach as an alternative to SA and to eliminate the uncertainty 
around the choice of the preferred correction factor used with SA. In-depth analysis of 2 data sets, one containing 50 compounds $^{1}$ (Table I) and the other containing 102 compounds, ${ }^{2}$ was performed to estimate human clearance, and results of that analysis were compared to the observed values. Percentage fold error has often been used to determine the strength of a given technique ${ }^{6}$; in this case, we used 1.5-, 2-, and 3-fold error as the criteria to evaluate number of failures in our predictions. From a drug discovery perspective, 2 - and 3-fold errors have been acceptable, ${ }^{6}$ whereas a 1.5 -fold error prediction is often desirable for the compound in clinical development. ${ }^{7}$ The goal was to minimize the number of outliers within these 1.5-, 2-, and 3-fold errors when predicting human clearance from preclinical species.

\section{METHODS}

For the purpose of exploring the accuracy and precision of human clearance estimates via allometric methods, we chose 2 of the largest and most diverse data sets in the current literature. Data set I, compiled by Mahmood, ${ }^{1}$ contains preclinical and clinical estimates of clearance for 50 compounds from a variety of chemical classes and clinical indications (Table I). For each compound, preclinical data included pharmacokinetic parameters from at least 3 separate species except cisplatinum, in which only 2 species were used (Table I). Data set II, compiled by Jolivette and Ward, ${ }^{2}$ contains results for 102 compounds obtained from rat, dog, and monkey. Data from iododoxorubicin were not included in the analysis because it was an obvious outlier and was excluded by other groups in the analysis. ${ }^{6}$ For the purpose of determining the effect of the number of preclinical species on the outcome of allometric scaling, the 2 data sets were analyzed separately using the schematic as depicted in Figure 1. Both SA and MA were conducted on data set I of 50 compounds, whereas SA, MLBF technique, and MA were conducted on 102 compounds of data set II. After this analysis, 33 compounds that were common to both publications were identified. For these 33 common compounds, SA and MA were conducted on those from data set I, whereas SA, MLBF technique, and MA were conducted on those data obtained from data set II. The 33 common compounds obtained from data set I were further evaluated for the impact of species selection on outcome of estimated clearance. Of those 33 common compounds obtained from data set I, 27 compounds were identified as having monkey as 1 of the species. These 27 compounds were further evaluated with SA and MA with and without monkey included as one of the species. These 27 compounds were also evaluated using the MLBF technique.

\section{Simple Allometry}

Clearances from various preclinical species were used to estimate human clearance CL in milliliters/minute using the slope $(b)$ and the coefficient of (a) SA as shown in equation 1.

$$
C L=a B W^{b}
$$

\section{Monkey Liver Blood Flow Technique}

The MLBF technique was performed using equation 2:

$$
C L_{\text {human }}=C L_{\text {monkey }}\left(L B F_{\text {human }} / L B F_{\text {monkey }}\right) \text {, }
$$

where $L B F$ is the liver blood flow of human or monkey, and the subscript of $C L$ denotes the clearance of human or monkey in milliliters/minute.

\section{Multiexponential Allometric Techniques}

Human clearance from MA was calculated using equation 3 :

$$
C L=a B W^{b}+c B W^{d}
$$

where $a$ and $b$ are the coefficient and slope from SA, and $d$ is the slope and $c$ the coefficient of MA. The derivation of the parameters $c$ and $d$ is detailed below.

\section{Determination of Slope for MA}

Blood flow rate, organ volume, and organ weight of liver and kidney of preclinical species ${ }^{9}$ were plotted against body weight. The slope of weight, volume, and organ flow rates of these major excretory organs (liver and kidney) were very similar and were approximately equal to 0.9 (Figure 2). The slope $d$ of the MA was fixed as 0.9 , the slope of these excretory organs.

\section{Determination of Coefficient for MA}

The coefficient of MA, $c$, was found to be a function of the coefficient of SA, $a$, as shown in equation 4 . 
Table I Species, Human Data, and Compounds Used in Data Set I

\begin{tabular}{|c|c|c|}
\hline Compound & Species & Reference \\
\hline Acivicin $^{\mathrm{a}}$ & ms, rt, mk (C, R), dg & 13 \\
\hline Actisomide $^{\mathrm{a}}$ & $\mathrm{rt}, \mathrm{dg}, \mathrm{mk}$ & 14 \\
\hline Amascarine & $\mathrm{ms}, \mathrm{rt}, \mathrm{rb}, \mathrm{dg}$ & 15 \\
\hline Amphotericin $\mathrm{B}^{\mathrm{a}}$ & $\mathrm{ms}, \mathrm{rt}, \mathrm{mk}, \mathrm{dg}$ & 16 \\
\hline Antipyrine $^{\mathrm{a}}$ & $\mathrm{ms}, \mathrm{rt}, \mathrm{rb}, \mathrm{dg}, \mathrm{mk}$ & 12,17 \\
\hline Ara-C & $\mathrm{ms}, \mathrm{mk}, \mathrm{dg}$ & 18 \\
\hline Caffeine $^{\mathrm{a}}$ & $\mathrm{ms}, \mathrm{rt}, \mathrm{rb}, \mathrm{mk}$ & 19 \\
\hline Candoxatril & $\mathrm{ms}, \mathrm{rt}, \mathrm{rb}, \mathrm{dg}$ & 20 \\
\hline Cefazolin ${ }^{\mathrm{a}}$ & $\mathrm{ms}, \mathrm{rt}, \mathrm{rb}, \mathrm{dg}, \mathrm{mk}$ & 21 \\
\hline Cefodizime $^{\mathrm{a}}$ & $\mathrm{ms}, \mathrm{rt}, \mathrm{rb}, \mathrm{dg}, \mathrm{mk}$ & 22 \\
\hline Cefoperazone $^{a}$ & $\mathrm{~ms}, \mathrm{rt}, \mathrm{rb}, \mathrm{dg}, \mathrm{mk}$ & 21 \\
\hline Cefotetan $^{\mathrm{a}}$ & $\mathrm{ms}, \mathrm{rt}, \mathrm{rb}, \mathrm{dg}, \mathrm{mk}$ & 21,22 \\
\hline Ceftizoxime $^{\mathrm{a}}$ & $\mathrm{ms}, \mathrm{rt}, \mathrm{mk}, \mathrm{dg}$ & 23 \\
\hline CI-1007 & $\mathrm{rt}, \mathrm{mk}, \mathrm{dg}$ & 24 \\
\hline CI-921 & $\mathrm{ms}, \mathrm{rt}, \mathrm{rb}, \mathrm{dg}$ & 15 \\
\hline Cisplatinum & $\mathrm{rb}, \mathrm{dg}$ & 25 \\
\hline Citalopram $^{\mathrm{a}}$ & $\mathrm{bb}, \mathrm{dg}, \mathrm{rt}, \mathrm{ms}$ & 26 \\
\hline Coumarin $^{\mathrm{a}}$ & $\mathrm{rt}, \mathrm{rb}, \mathrm{mk}, \mathrm{dg}, \mathrm{sh}$ & 27 \\
\hline Cyclophosphamide $^{\mathrm{a}}$ & $\mathrm{ms}, \mathrm{hs}, \mathrm{rt}, \mathrm{dg}, \mathrm{mk}$ & 28 \\
\hline Cyclosporin & $\mathrm{rt}, \mathrm{rb}, \mathrm{dg}$ & 29 \\
\hline Diazepam & $\mathrm{rt}, \mathrm{gp}, \mathrm{rb}, \mathrm{dg}$ & 30 \\
\hline Erythromycin ${ }^{a}$ & $\mathrm{~ms}, \mathrm{rt}, \mathrm{rb}, \mathrm{dg}, \mathrm{cw}$ & 31 \\
\hline Ethusuximide $^{a}$ & $\mathrm{~ms}, \mathrm{rt}, \mathrm{rb}, \mathrm{dg}$ & 17,32 \\
\hline Fentanyl $^{\mathrm{a}}$ & $\mathrm{rt}, \mathrm{dg}, \mathrm{pg}, \mathrm{mk}$ & 33,34 \\
\hline Furosemide $^{a}$ & $\mathrm{mk}(\mathrm{C}, \mathrm{R}), \mathrm{bb}, \mathrm{dg}, \mathrm{rt}$ & $35-37$ \\
\hline GV150526 & $\mathrm{rt}, \mathrm{dg}, \mathrm{mk}$ & 38 \\
\hline Inogatran $^{a}$ & $\mathrm{rt}, \mathrm{dg}, \mathrm{mk}$ & 39,40 \\
\hline ITF-296 & $\mathrm{rt}, \mathrm{dg}, \mathrm{mk}$ & $41-44$ \\
\hline Ketorolac $^{\mathrm{a}}$ & $\mathrm{ms}, \mathrm{rt}, \mathrm{rb}, \mathrm{mk}$ & 45 \\
\hline Lamifiban $^{\mathrm{a}}$ & $\mathrm{rt}, \mathrm{dg}, \mathrm{mk}$ & 46 \\
\hline Meropenem $^{a}$ & $\mathrm{rt}, \mathrm{dg}, \mathrm{mk}$ & 47 \\
\hline Methotrexate $^{\mathrm{a}}$ & $\mathrm{ms}$, rat, dg mk & 48 \\
\hline Metoprolol $^{\mathrm{a}}$ & $\mathrm{rt}, \mathrm{rb}, \mathrm{mk}, \mathrm{dg}$ & $49-52$ \\
\hline Midazolam & $\mathrm{ms}, \mathrm{rt}, \mathrm{dg}$ & $53-56$ \\
\hline Moxalactam & $\mathrm{ms}, \mathrm{rt}, \mathrm{rb}, \mathrm{dg}, \mathrm{mk}$ & 21 \\
\hline Nicardipine $^{\mathrm{a}}$ & $\mathrm{rt}, \mathrm{dg}, \mathrm{mk}$ & 57 \\
\hline Ofloxacin & $\mathrm{rt}, \mathrm{rb}, \mathrm{dg}$ & 58 \\
\hline Oleandomycin & $\mathrm{ms}, \mathrm{rt}, \mathrm{dg}$ & 31 \\
\hline Pelrinone $\mathrm{HCL}^{\mathrm{a}}$ & $\mathrm{ms}, \mathrm{rt}, \mathrm{rb}, \mathrm{dg}, \mathrm{mk}$ & 59 \\
\hline Phencyclidine $^{\mathrm{a}}$ & $\mathrm{ms}, \mathrm{rt}, \mathrm{pn}, \mathrm{mk}, \mathrm{dg}$ & 60 \\
\hline Phenytoin ${ }^{\mathrm{a}}$ & $\mathrm{rt}, \mathrm{rb}, \mathrm{dg}$, gt & 61 \\
\hline Propranolol $^{\mathrm{a}}$ & $\mathrm{rt}, \mathrm{dg}, \mathrm{mk}$ & 49,62 \\
\hline Quinidine $^{\mathrm{a}}$ & $\mathrm{ms}, \mathrm{rb}, \mathrm{mk}$ & $63-65$ \\
\hline Sildenafil & $\mathrm{ms}, \mathrm{rt}, \mathrm{rb}, \mathrm{dg}$ & 66 \\
\hline Stavudine & $\mathrm{ms}, \mathrm{rt}, \mathrm{rb}, \mathrm{mk}$ & 67,68 \\
\hline Tebufelone $^{\mathrm{a}}$ & $\mathrm{rt}, \mathrm{mk}, \mathrm{dg}$ & 69 \\
\hline Theophylline & $\mathrm{rt}, \mathrm{rb}, \mathrm{dg}$ & 70 \\
\hline Trimethedione $^{\mathrm{a}}$ & $\mathrm{ms}, \mathrm{hs}, \mathrm{rt}, \mathrm{rb}, \mathrm{dg}, \mathrm{mk}$ & 71 \\
\hline Valproic acid ${ }^{\mathrm{a}}$ & $\mathrm{ms}, \mathrm{rt}, \mathrm{dg}$ & 17,72 \\
\hline Warfarin $^{\mathrm{a}}$ & $\mathrm{rt}, \mathrm{rb}, \mathrm{dg}$ & 17 \\
\hline
\end{tabular}

bb, baboon; cw, cow; dg, dog; gt, goat; hs, hamster; mk, monkey (C, cymologous; R, rhesus); ms, mouse; pg, pig; pn, pigeon; rb, rabbit; rt, rat; sh, sheep. ${ }^{1}$ a. Compounds common to data set I and data set II. 


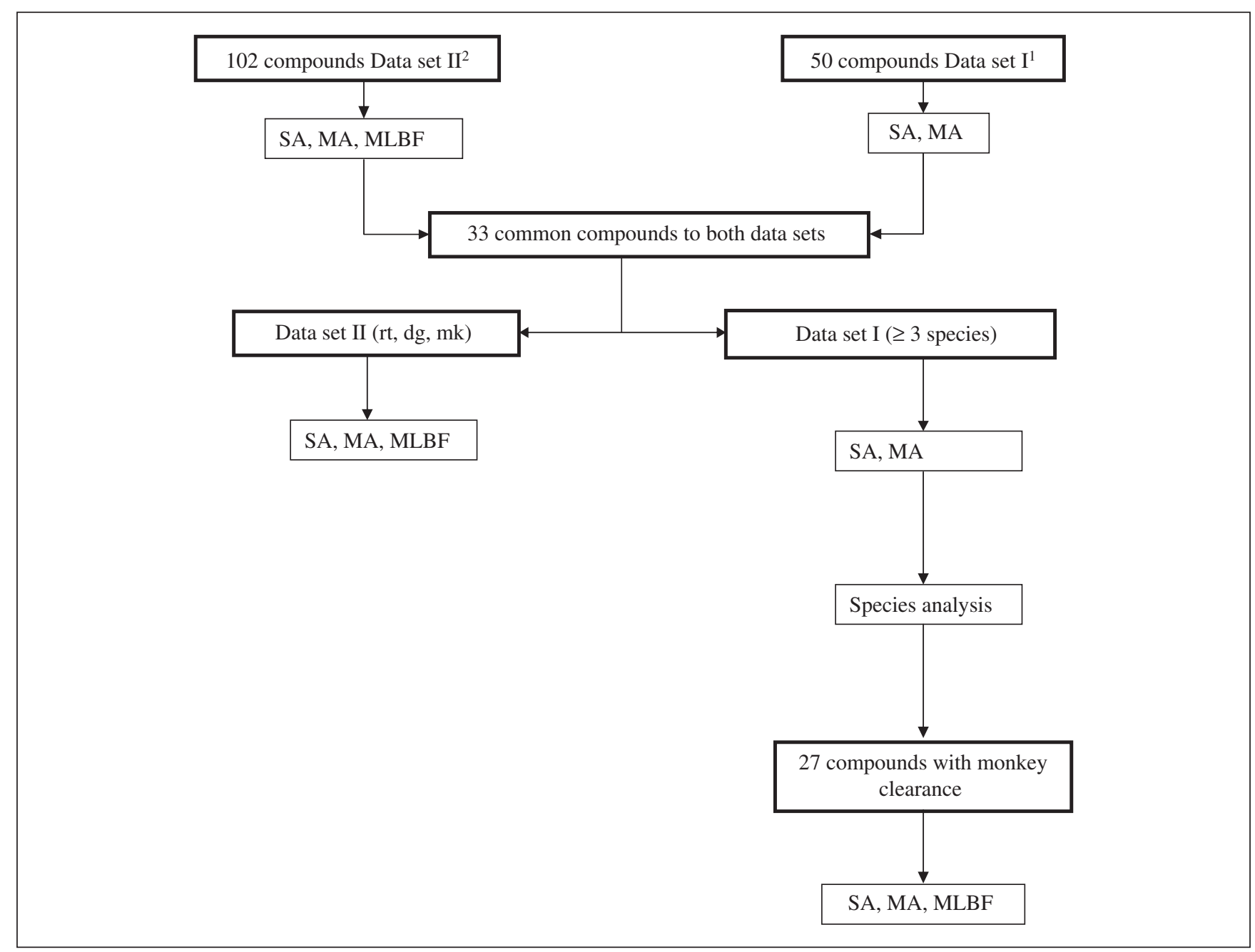

Figure 1 Schematic depicting the strategy employed for evaluating each technique and data set. dg, dog; MA, multiexponential allometry; mk, monkey; $M L B F$, monkey liver blood flow; rt, rat; $S A$, simple allometry.

$$
c=\beta^{*} a
$$

After analysis of both data sets, that is, keeping one as the training set and the other as an experimental set and vice-versa, it was found that the parameter $\beta$ was a function of the slope of SA and was approximated and expressed according to equation 5:

$$
\beta=\frac{\left(1-\frac{3}{2} b\right)}{\left(1-\frac{1}{2} b\right)}
$$

where $\beta$ is the adaptive coefficient, and $b$ is the slope of SA. Equation 3 was thus modified to equation
6 using equations 4 and 5 to calculate human clearance:

$$
C L=a B W^{b}+\left[\frac{\left(1-\frac{3}{2} b\right)}{\left(1-\frac{1}{2} b\right)}\right] a B W^{0.9}
$$

\section{Comparison Between SA, MLBF, and MA}

Fold error was calculated using each of the allometric techniques for both data sets using equation 7 :

$$
F E=\frac{C L_{\text {predicted }}}{C L_{\text {observed }}}
$$




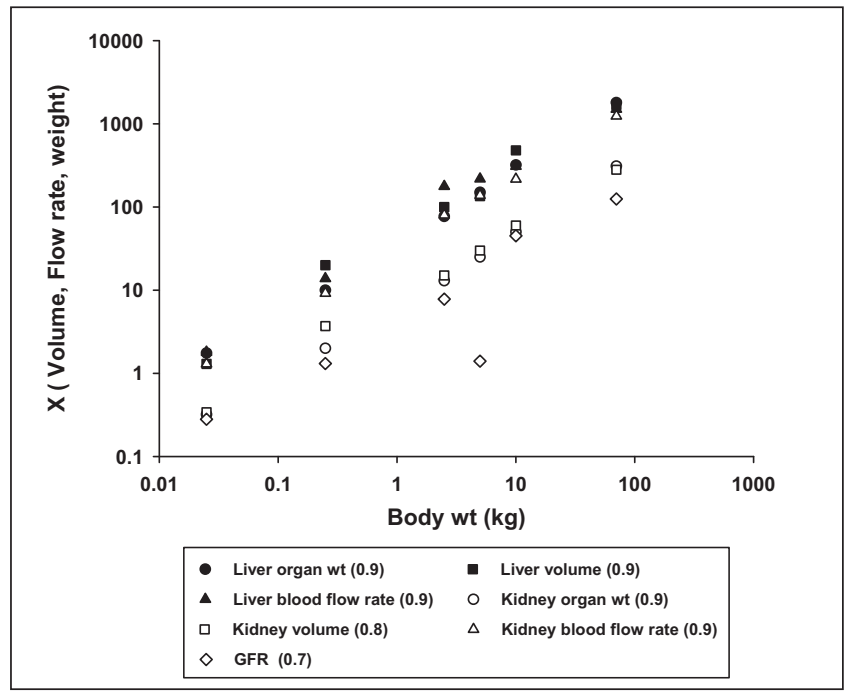

Figure 2. Organ weight (wt), flow rate, and volume of 2 major excretory organs (liver and kidney) across species (mouse, rat, rabbit, dog, monkey, and human). The slope of the relationship is given in parentheses. GFR, glomerular filtration rate.

where $F E$ is fold error, $C L_{\text {predicted }}$ is predicted clearance, and $C L_{\text {observed }}$ is observed clearance.

The predictability of MA, MLBF, and SA was compared by calculating the percentage of outliers falling out of the 1.5-fold, 2-fold (0.5-2.0), and 3-fold (0.33-3.0) ranges. Average fold error (AFE) and average absolute fold error (AAFE) were also calculated for each data set and technique using the method of Obach et al. ${ }^{6,10}$

\section{RESULTS}

Using SA to estimate human drug clearance for data set I, the AFE and AAFE were 1.41 and 1.54, respectively. The MA analysis gave AFE and AAFE values of 1.19 and 1.54, respectively (Table II). With data set II, the AFE and AAFE using SA were 1.28 and 2.61, respectively, whereas for MA the corresponding values were 1.39 and 2.61, respectively (Table II). These results indicate that both techniques slightly overpredict human clearance in both data sets.

When using SA, the percentages of outliers falling outside the 1.5-, 2-, and 3-fold ranges were highest in both data sets. In data set I, the percentage of outliers falling outside 1.5-, 2-, and 3-fold ranges was $74 \%, 47 \%$, and $29 \%$, respectively. Within data set II, the percentage of outliers falling outside 1.5-, 2-, and 3 -fold ranges was $70 \%, 46 \%$, and $28 \%$, respectively, using SA (Figure 3). When using the MLBF technique, the percentage of outliers falling outside the
Table II Average Fold Error (AFE) and Average Absolute Fold Error (AAFE) Using SA and MA in Estimating Human Clearances

\begin{tabular}{lccccc}
\hline & \multicolumn{2}{c}{ Data Set I } & & \multicolumn{2}{c}{ Data Set II } \\
\cline { 2 - 3 } \cline { 6 - 6 } & SA & MA & & SA & MA \\
\hline AFE & 1.41 & 1.19 & & 1.28 & 1.39 \\
AAFE & 1.54 & 1.54 & & 2.61 & 2.61 \\
\hline
\end{tabular}

MA, multiexponential allometry; SA, simple allometry.

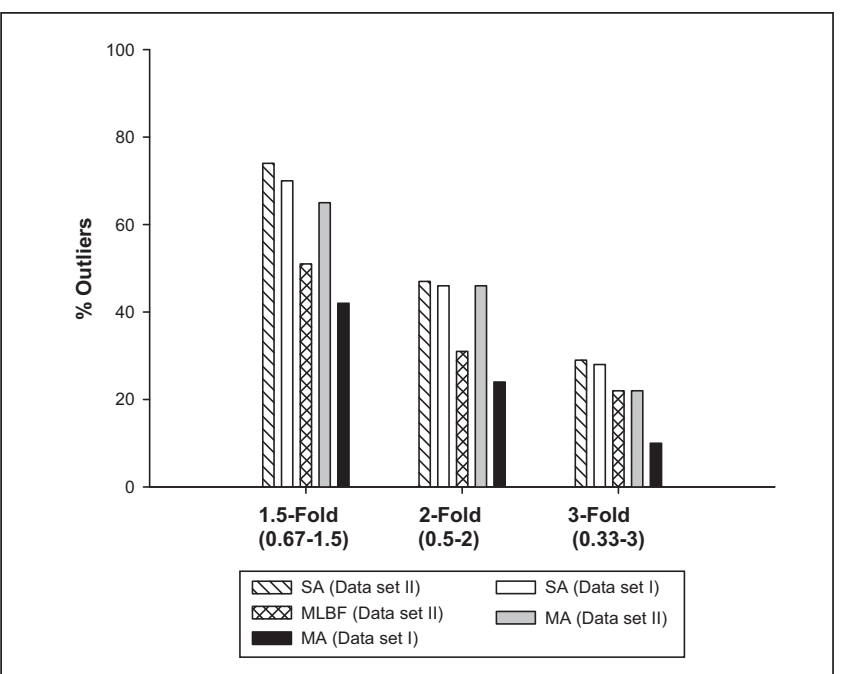

Figure 3. Comparison of error in the estimation of human drug clearance by simple allometry (SA), monkey liver blood flow $(M L B F)$ technique, and multiexponential allometry (MA) using 50 compounds from data set I and 102 compounds from data set II. Error was characterized as the percentages of outliers outside 1.5fold (0.67-1.5), 2-fold (0.5-2), and 3-fold (0.33-3) of actual measured values.

1.5-, 2-, and 3-fold ranges on data set II was roughly $50 \%, 30 \%$, and $25 \%$, respectively (Figure 3 ).

The percentage of outliers falling outside the 1.5-, 2-, and 3-fold ranges using the MA technique varied between the 2 data sets tested. In the case of data set I, the percentages of outliers from MA were approximately $42 \%, 24 \%$, and $10 \%$, respectively (Figure 3). This represents about a 50\% drop for 1.5-, 2-, and 3fold range outliers compared to the SA technique. Within data set 2 , the percentages of outliers were approximately $65 \%, 46 \%$, and $22 \%$, respectively (Figure 3).

There were 33 compounds common to both data sets. However, each data set had collected preclinical clearance data from different species. This offered an 


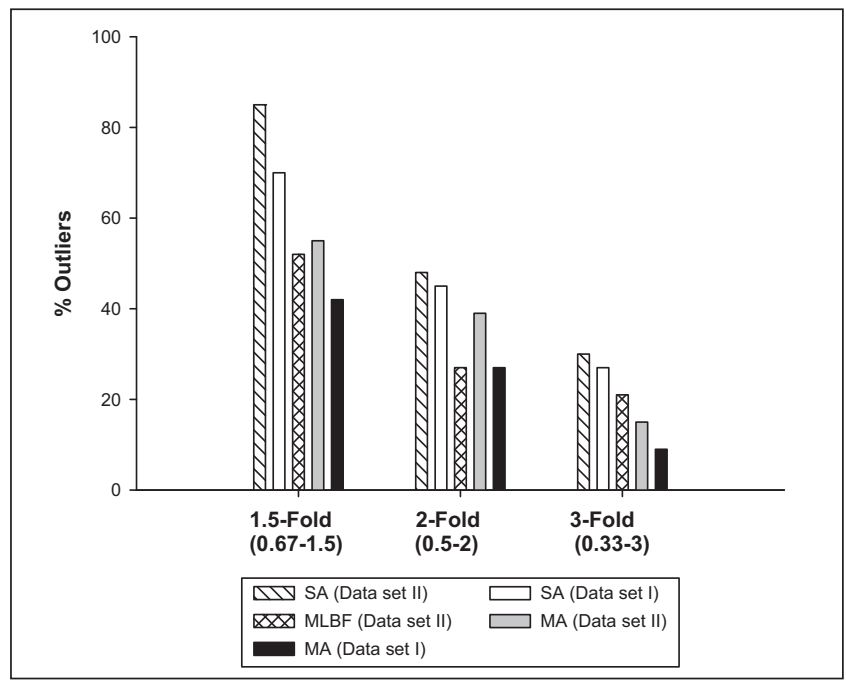

Figure 4. Comparison of error in the estimation of human drug clearance by simple allometry (SA), monkey liver blood flow (MLBF) technique, and multiexponential allometry (MA) using 33 compounds common to both data sets I and II. Error was characterized as with the percentages of outliers outside 1.5-fold (0.671.5), 2-fold (0.5-2), and 3-fold (0.33-3) of actual measured values. Comparison of SA, MLBF technique, and MA with the percentages of outliers outside 1.5-fold (0.67-1.5), 2-fold (0.5-2), and 3fold (0.33-3).

opportunity to assess the impact of species choice to accuracy of each method. When these 33 compounds common to both data sets (Table I) were further evaluated using SA, MLBF, and MA approaches, the results showed that the percentages of outliers falling outside the 1.5-, 2-, and 3-fold ranges were highest in both data sets when using SA (Figure 4). The percentage of outliers falling outside the 1.5-, 2-, and 3 -fold ranges in case of data set I was $70 \%, 45 \%$, and $27 \%$, respectively, whereas for data set II, they were $85 \%, 48 \%$, and $30 \%$, respectively, using SA (Figure 4). Using the MLBF technique, the percentage of outliers falling outside the 1.5-, 2-, and 3-fold ranges on data set II was $52 \%, 27 \%$, and $21 \%$, respectively (Figure 4). The percentage of outliers falling outside the 1.5-, 2-, and 3-fold ranges using the MA technique was $42 \%, 27 \%$, and $9 \%$, respectively, for data set I (Figure 4). For data set II, the percentage of outliers outside the 1.5-, 2-, and 3-fold ranges was approximately $55 \%$, 39\%, and $15 \%$, respectively, when using the MA technique (Figure 4).

When the subset of 33 compounds common to both data sets was further analyzed for the choice of species, it was found that for about $70 \%$ of the compounds, more than 3 preclinical species were used; for $80 \%$ of the compounds, the species were not restricted to the combination of rat, dog, and monkey.

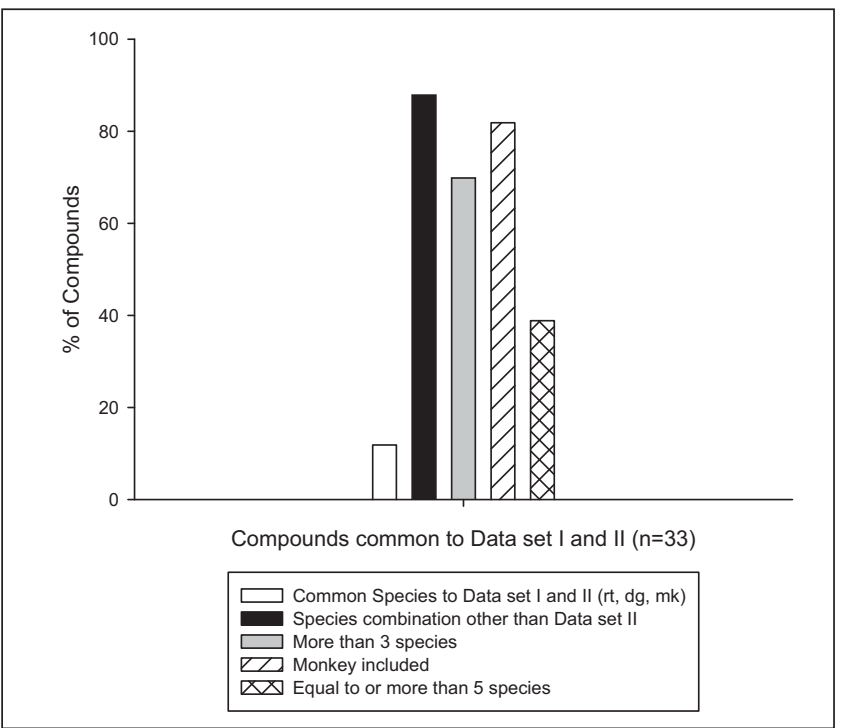

Figure 5. Species selection for 33 compounds common to both data sets I and II. dg, dog; mk, monkey; rt, rat.

Furthermore, monkey was one of the preclinical species for human clearance estimation for about $80 \%$ of the compounds (Figure 5). When 27 of these compounds that had monkey included as a preclinical species were further evaluated, it was found that including monkey as a species improved the human clearance estimates with both SA and MA methods (Figure 6). Using SA on these 27 compounds, the percentage of outliers falling outside the 1.5-, 2-, and 3 -fold ranges without monkey data was $85 \%, 74 \%$, and $59 \%$, respectively, versus $67 \%, 33 \%$, and $19 \%$, respectively, with monkey as one of the species (Figure 6). Using the MLBF technique, the percentage of outliers falling outside the 1.5-, 2-, and 3-fold ranges for these 27 compounds was $48 \%, 22 \%$, and $14 \%$, respectively (Figure 6). The percentage of outliers falling outside the 1.5-, 2-, and 3-fold ranges for these 27 compounds using the MA technique was $88 \%$, $70 \%$, and $48 \%$, respectively, without monkey included as one of the species (Figure 6). With monkey included as one of the species for these 27 compounds, the percentage of outliers outside the 1.5-, 2-, and 3fold ranges was approximately $37 \%, 22 \%$, and $4 \%$, respectively, when using the MA technique (Figure 6).

\section{DISCUSSION}

Accurate estimation of human clearance is a critical step in the estimation of human pharmacokinetics. 


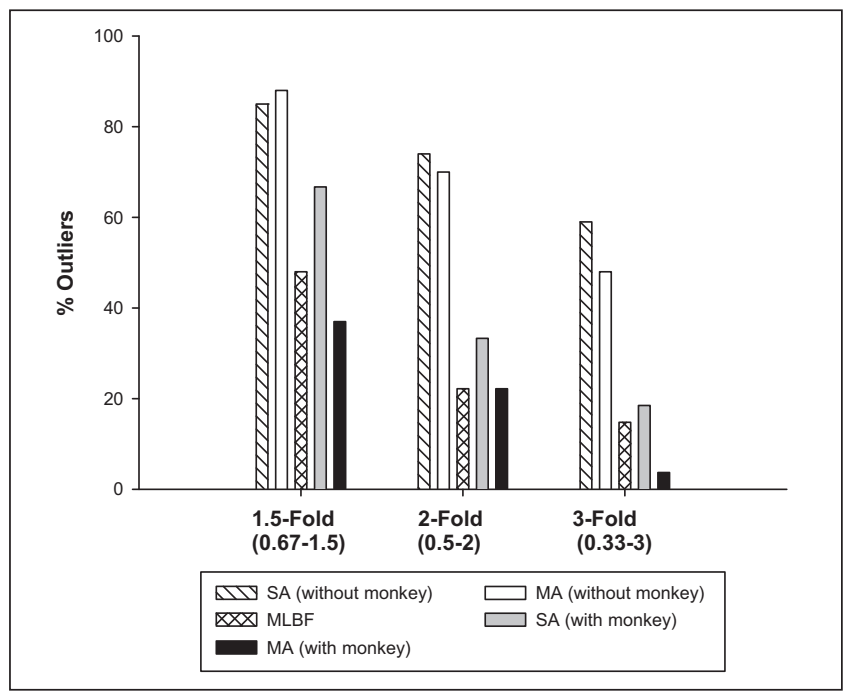

Figure 6. Comparison of simple allometry (SA), monkey liver blood flow (MLBF) technique, and multiexponential allometry (MA) on 27 compounds (with and without monkey data from data set I).

Although there have been several articles outlining the poor predictability of allometric techniques, ${ }^{11}$ allometry is still widely used in the estimation of human clearance using information from preclinical species. This study aimed at increasing the predictability of human clearances using MA compared to the SA method without additional experimental work. The MA method also eliminates the uncertainty of the choice of the proper correction factor when SA is used to predict clearance.

Analysis of data set I (50 compounds) and data set II (102 compounds) separately rather than in combination was useful for understanding the likelihood of particular technique to minimize the error in human clearance predictions within 1.5-, 2-, and 3-fold. The results from this study showed that when SA was used to estimate human clearances for either set of data, the predictions do not differ very much, suggesting the limitation of the technique. In fact, SA always gave the largest number of outliers outside 1.5-, 2-, and 3-fold compared to MLBF or MA, and analysis was independent of the data sets.

Analysis of the 33 compounds common to both sets was also helpful in understanding the impact of the number and choice of species required to minimize the error in the human clearance prediction using any technique. Analysis of the 2 data sets showed that approximately $88 \%$ of the time, the combination of species was different between data sets; that is, they were not necessarily a combination of rat, dog, and monkey (Table I and Figure 5). When SA was used to estimate the clearance of the 33 compounds common to both data sets, the percentage of predictions outside $1.5-, 2-$, and 3 -fold ranges was within $5 \%$ error compared to the analysis of the complete data sets. The analysis of 27 compounds showed that including monkey as one of the species could improve SA predictions significantly by reducing the outliers by almost $50 \%$ at 2 - and 3 -fold levels. However, SA still remained the worst predictor of human clearance compared to MLBF or MA. This suggests that the benefit from using more than 3 species (ie, data set I) or monkey as a preclinical species is minimal with SA, especially at 1.5-fold level.

When using more than 3 species, the MA technique, when applied to these 33 common compounds, enhanced the capability of predicting human clearance by reducing the 1.5-, 2-, and 3-fold outliers by approximately $50 \%$ (data set 1 ) relative to results when SA was used. The reduction in 1.5-, 2-, and 3-fold outliers was less significant using the MA technique on data set II for these 33 compounds when compared to SA. Because data set II was limited to only 3 species (rat, monkey, and dog), this suggests that maximal improvement in the accuracy of human clearance estimation by MA requires at least 3 or more species, and the species selection should not be limited or restricted to the combination of rat, dog, and monkey. Analysis of 27 compounds that had monkey data within data set I suggested that monkey is an important species for interspecies scaling, and inclusion of monkey reduced the percentage outliers when using MA. Including monkey as a species in MA was shown to capture $95 \%$ of estimates within 3 -fold of the measured value (Figure 6).

When compounds in data set II that did not meet the 3-fold criteria were reanalyzed, some of these had renal or biliary clearances as a predominant route of elimination. After reanalysis using SA after excluding 13 compounds from data set II with biliary or renal route of elimination (actisomide, betamipron, cefazolin, cefmetazole, cefoperazone, cefotetan, cefpiramide, ciprofloxacin, moxifloxacin, napsagatran, susalimod, ethinylestradiol, Ro25-6833), ${ }^{1}$ the percentage of outliers outside 1.5-, 2-, and 3-fold was $72 \%, 47 \%$, and $30 \%$, respectively. With the MA technique for these 89 compounds, the percentage of outliers outside 1.5-, 2-, and 3-fold was $62 \%, 43 \%$, and $19 \%$, respectively, whereas with MLBF percentage was $51 \%, 33 \%$, and $25 \%$, respectively. Thus, if the mechanism of clearance in preclinical species is understood, then MA could improve the predictions and reduce the percentage of outliers within 3 -fold 
error better than the MLBF method could. One hypothesis could be that the compounds with renal elimination may be influenced by glomerular filtration rate whose exponents are 0.7 and not 0.9 across species. Further work is warranted in this direction to study the impact of different values of $d$ on the human clearance predictions.

The percentages of outliers within the 1.5- and 2fold were best estimated by the MLBF technique for data set II. Similar results were obtained by Tang et al, ${ }^{6}$ suggesting that MLBF methods are a very useful means of estimating human clearance. However, the current analyses of data sets with 33 common compounds suggest that by using MA with more than 3 species including monkey, it is possible to estimate human clearance within 1.5 -fold $60 \%$ of the time, within 2 -fold $80 \%$ of the time, and within 3 -fold more than $90 \%$ of the time. This represents an improvement of approximately $50 \%$ compared to the MLBF technique alone at 3-fold outliers. Moreover, the MLBF technique is a single-species approach, and errors in the clearance estimate of monkey could lead to error in human clearance estimation. For example, various antipyrine monkey clearance estimates have been reported in the literature $\left(4.4\right.$ and $11.5 \mathrm{~mL} / \mathrm{min} / \mathrm{kg}$ ). ${ }^{2,12}$ Thus, estimation of human clearance would vary (Table III) depending on which monkey clearance value is used. Therefore, the use of the MLBF technique alone should be used with caution for human clearance predictions. The MA technique offers the benefit of dampening the impact of an error in the estimate of clearance for any given species.

Although using SA led to the greatest number of outliers in our analysis, it is important to note that SA can be useful in a majority of cases. For example, when data set I (50 compounds) was broken down into 3 categories based on the SA slopes of 0.3 to 0.5 , 0.51 to 0.7 , and $>0.71$, it was found that when the slopes of SA were less than 0.7 , predictions after SA were equal to predictions from MA (Figure 7). However the number of compounds with slope 0.3 to 0.5 and 0.51 to 0.7 only accounted for $4(8 \%)$ and 13 compounds (26\%) of the total 50 compounds in data set I, respectively. When the slope was $>0.7$, then MA had a clear advantage over SA, and the number of compounds with $>0.7$ slope was $33(66 \%)$ of the 50 compounds used in data set I. That is, the MA technique extends the range wherein allometric techniques may be considered to be accurate and useful.
Table III Fold Error of Predicted Human Clearance of Antipyrine Using Various Data Sets

\begin{tabular}{lccc}
\hline Data Source & SA & MA & MLBF \\
\hline Lave et al $^{73}$ & 7.7 & 2.7 & \\
Jolivette and Ward $^{2}$ & 4.8 & 2.3 & 3.1 \\
Balani et al $^{12}$ & 9.8 & 3.9 & 8.2 \\
Bachmann $^{17}$ & 1.3 & 2.0 & \\
\hline
\end{tabular}

MA, multiexponential allometry; MLBF, monkey liver blood flow; SA, simple allometry.

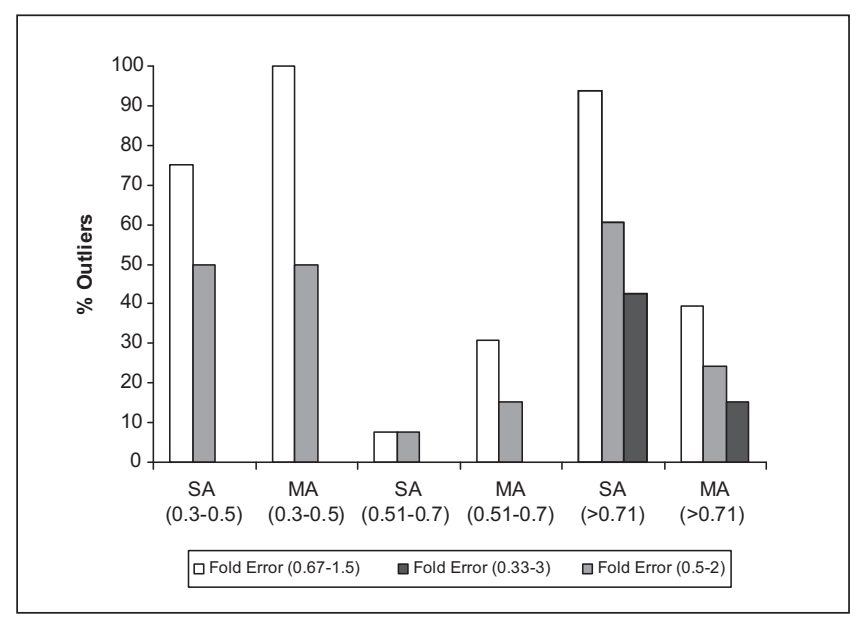

Figure 7. Error analysis of data set I using simple allometry (SA) and multiexponential allometry (MA) grouped by allometric slopes.

In summary, these results show that the MA technique, when used with preclinical data from more than 3 species, is an improved means of estimating human clearance within acceptable criteria for error. The results also show that SA is not the best technique to predict human clearance in all cases. Furthermore, the MLBF technique should be used with caution because it is a 1-species method for estimating human clearance. The MA and MLBF techniques can be more predictive as measured by the number of estimates within 1.5-, 2-, or 3-fold error. The results also suggest that the MA technique when applied to data sets from more than 3 species with monkey included should be able to predict human clearance with much reduced error compared to the MLBF technique. 


\section{APPENDIX}

It is well known that basic anabolic metabolism or energy usage is proportional to body mass, and the slope of this relationship is approximately $2 / 3(0.67) .{ }^{1}$ However, as shown in the body of this article, cellularity and therefore volumes of the eliminating organs (liver and kidney) scale against body weight with a slope of approximately 0.9. In an integrated biological system, drug metabolism capacity is a function of the volume of cells mediating drug elimination within an organ; therefore, both anatomical and physiological processes have to be taken into account for scaling drug clearance. The separate scaling factors associated with energy usage and volumes of eliminating organs served as the conceptual basis for multiexponential allometry (MA).

It is established that the simple allometric (SA) slope $(a)$ and exponent $(b)$ approximate the relationship between energy use and metabolic capacity (equation A1):

$$
C l_{o b s}=a B W^{b} .
$$

We hypothesize that the errors in this relationship observed when the slope and exponents are outside of a known boundary ${ }^{1}$ can be minimized by addition of exponential terms that account for anatomical capacity (equation A2):

$$
C l_{o b s}=a B W^{b}+c B W^{d},
$$

where $a$ and $b$ are the coefficient and slope from SA, and $d$ is the slope and $c$ the coefficient of MA. The explicit derivation of the parameters $c$ and $d$ is detailed below.

\section{Determination of Slope for MA}

Blood flow rate, organ volume, and organ weight of liver and kidney of preclinical species ${ }^{9}$ were plotted against body weight. The slope of weight, volume, and organ flow rates of these major excretory organs, that is, liver and kidney, were very similar and approximately equal to 0.9 (Figure 2). The slope $d$ of the MA was fixed as 0.9 , the slope of these excretory organs.

\section{Determination of Coefficient for MA}

The coefficient $c$ in equation A2 is a function of the coefficient of SA $a$ and a modifier $\beta$ :

$$
c=\beta^{*} a .
$$

This modifier $\beta$, or adaptive coefficient, can be derived from the multiexponential function in equation A2,

$$
C l_{o b s}=a B W^{b}+\beta a B W^{d},
$$

by rearranging to solve for $\beta$ :

$$
\beta=\frac{C l_{o b s}-a B W^{b}}{a B W^{d}} .
$$

The values of the parameter $\beta$ were derived from an empirical analysis of the major clinical data sets referenced within the main text. Using data from the 119 compounds in those data sets, the relationship between $\beta$ and slope of SA $b$ could be expressed as $(1-A x) /(1-$ $B x$ ), where $A$ and $B$ were 1.39 to 1.49 and 0.53 to 0.61 , respectively. To simplify, these values were approximated to 1.5 and 0.5 for $A$ and $B$, respectively. This approximation yields the final term:

$$
\beta=\frac{\left(1-\frac{3}{2} b\right)}{\left(1-\frac{1}{2} b\right)}
$$

where $\beta$ is the adaptive coefficient, and $b$ is the slope of SA.

The final equation can be used to calculate estimated clearance:

$$
C l_{\text {pred }}=a B W^{b}+\left[\frac{\left(1-\frac{3}{2} b\right)}{\left(1-\frac{1}{2} b\right)}\right] a B W^{0.9} .
$$


Financial disclosure: None declared.

\section{REFERENCES}

1. Mahmood I. Interspecies Pharmacokinetic Scaling. Rockville, Md: Pine House Publishers; 2005.

2. Jolivette LJ, Ward KW. Extrapolation of human pharmacokinetic parameters from rat, dog, and monkey data: molecular properties associated with extrapolative success or failure. J Pharm Sci. 2005;94:1467-1483.

3. Adolph EF. Quantitative relations in the physiological constitutions of mammals. Science. 1949;109:579-585.

4. Dedrick RL. Animal scale-up. J Pharmacokinet Biopharm. 1973;1:435-461

5. Mahmood I, Balian JD. Interspecies scaling: predicting clearance of drugs in humans. Three different approaches. Xenobiotica. 1996;26:887-895.

6. Tang $\mathrm{H}$, Hussain $\mathrm{A}$, Leal $\mathrm{M}$, et al. Interspecies prediction of human drug clearance based on scaling data from one or two animal species. Drug Metab Dispos. 2007;35:1886-1893.

7. Ward KW, Smith BR. A comprehensive quantitative and qualitative evaluation of extrapolation of intravenous pharmacokinetic parameters from rat, dog, and monkey to humans, I: clearance. Drug Metab Dispos. 2004;32:603-611.

8. Lave T, Coassolo P, Reigner B. Prediction of hepatic metabolic clearance based on interspecies allometric scaling techniques and in vitro-in vivo correlations. Clin Pharmacokinet. 1999;36: 211-231.

9. Davies B, Morris T. Physiological parameters in laboratory animals and humans. Pharm Res. 1993;10:1093-1095.

10. Obach RS, Baxter JG, Liston TE, et al. The prediction of human pharmacokinetic parameters from preclinical and in vitro metabolism data. J Pharmacol Exp Ther. 1997;283:46-58.

11. Nagilla R, Ward KW. A comprehensive analysis of the role of correction factors in the allometric predictivity of clearance from rat, dog, and monkey to humans. J Pharm Sci. 2004;93:2522-2534.

12. Balani SK, Zhu T, Yang TJ, et al. Effective dosing regimen of 1-aminobenzotriazole for inhibition of antipyrine clearance in rats, dogs, and monkeys. Drug Metab Dispos. 2002;30:1059-1062. 13. McGovren JP, Williams MG, Stewart JC. Interspecies comparison of acivicin pharmacokinetics. Drug Metab Dispos. 1988; 16:18-22.

14. Cook CS, Rozek LF, Stolzenbach J, et al. Pharmacokinetics of a novel antiarrhythmic drug, actisomide. Pharm Res. 1993;10: 427-433.

15. Paxton JW, Kim SN, Whitfield LR. Pharmacokinetic and toxicity scaling of the antitumor agents amsacrine and CI-921, a new analogue, in mice, rats, rabbits, dogs, and humans. Cancer Res. 1990;50:2692-2697.

16. Hutchaleelaha A, Chow HH, Mayersohn M. Comparative pharmacokinetics and interspecies scaling of amphotericin B in several mammalian species. J Pharm Pharmacol. 1997;49:178-183.

17. Bachmann K. Predicting toxicokinetic parameters in humans from toxicokinetic data acquired from three small mammalian species. J Appl Toxicol. 1989;9:331-338.

18. Dedrick RL, Forrester DD, Cannon JN, et al. Pharmacokinetics of 1-beta-D-arabinofuranosylcytosine (ARA-C) deamination in several species. Biochem Pharmacol. 1973;22:2405-2417.
19. Bonati M, Latini R, Tognoni G, et al. Interspecies comparison of in vivo caffeine pharmacokinetics in man, monkey, rabbit, rat, and mouse. Drug Metab Rev. 1984;15:1355-1383.

20. Kaye B, Brearley CJ, Cussans NJ, et al. Formation and pharmacokinetics of the active drug candoxatrilat in mouse, rat, rabbit, dog and man following administration of the prodrug candoxatril. Xenobiotica. 1997;27:1091-1102.

21. Sawada Y, Hanano M, Sugiyama Y, et al. Prediction of the disposition of beta-lactam antibiotics in humans from pharmacokinetic parameters in animals. J Pharmacokinet Biopharm. 1984;12: 241-261.

22. Matsushita H, Suzuki H, Sugiyama Y, et al. Prediction of the pharmacokinetics of cefodizime and cefotetan in humans from pharmacokinetic parameters in animals. J Pharmacobiodyn. 1990; 13:602-611.

23. Mordenti J. Pharmacokinetic scale-up: accurate prediction of human pharmacokinetic profiles from animal data. J Pharm Sci. 1985;74:1097-1099.

24. Feng MR, Loo J, Wright J. Disposition of the antipsychotic agent CI-1007 in rats, monkeys, dogs, and human cytochrome P450 2D6 extensive metabolizers: species comparison and allometric scaling. Drug Metab Dispos. 1998;26:982-988.

25. King FG, Dedrick RL, Farris FF. Physiological pharmacokinetic modeling of cis-dichlorodiammineplatinum(II) (DDP) in several species. J Pharmacokinet Biopharm. 1986;14:131-155.

26. Fredricson Overo K. Kinetics of citalopram in test animals: drug exposure in safety studies. Prog Neuropsychopharmacol Biol Psychiatry. 1982;6:297-309.

27. Ritschel WA, Vachharajani NN, Johnson RD, et al. Interspecies scaling of the pharmacokinetic parameters of coumarin among six different mammalian species. Methods Find Exp Clin Pharmacol. 1991;13:697-702.

28. Mellett LB. Comparative drug metabolism. Prog Drug Res. 1969;13:136-169.

29. Sangalli L, Bortolotti A, Jiritano L, et al. Cyclosporine pharmacokinetics in rats and interspecies comparison in dogs, rabbits, rats, and humans. Drug Metab Dispos. 1988;16:749-753.

30. Klotz U, Antonin KH, Bieck PR. Pharmacokinetics and plasma binding of diazepam in man, dog, rabbit, guinea pig and rat. $J$ Pharmacol Exp Ther. 1976;199:67-73.

31. Duthu GS. Interspecies correlation of the pharmacokinetics of erythromycin, oleandomycin, and tylosin. J Pharm Sci. 1985;74: 943-946.

32. el Sayed MA, Loscher W, Frey HH. Pharmacokinetics of ethosuximide in the dog. Arch Int Pharmacodyn Ther. 1978;234:180-192.

33. Valverde CR, Mama KR, Kollias-Baker C, et al. Pharmacokinetics and cardiopulmonary effects of fentanyl in isoflurane-anesthetized rhesus monkeys (Macaca mulatta). Am J Vet Res. 2000;61:931-934.

34. Bjorkman S, Redke F. Clearance of fentanyl, alfentanil, methohexitone, thiopentone and ketamine in relation to estimated hepatic blood flow in several animal species: application to prediction of clearance in man. J Pharm Pharmacol. 2000;52:1065-1074.

35. Doyle E, Chasseaud LF, Miller JN. Comparative pharmacokinetics of frusemide in female rhesus monkeys, cynomolgus monkeys and baboons. Comp Biochem Physiol C. 1982;71C:89-93.

36. Hirai J, Miyazaki H, Taneike T. The pharmacokinetics and pharmacodynamics of furosemide in the anaesthetized dog. J Vet Pharmacol Ther. 1992;15:231-239. 
37. Prandota J, Pruitt AW. Pharmacokinetic, biliary excretion, and metabolic studies of 14C-furosemide in the rat. Xenobiotica. 1991;21:725-736.

38. Iavarone L, Hoke JF, Bottacini M, et al. First time in human for GV196771: interspecies scaling applied on dose selection. J Clin Pharmacol. 1999;39:560-566.

39. Eriksson UG, Renberg L, Bredberg U, et al. Animal pharmacokinetics of inogatran, a low-molecular-weight thrombin inhibitor with potential use as an antithrombotic drug. Biopharm Drug Dispos. 1998;19:55-64.

40. Hauptmann J. Pharmacokinetics of an emerging new class of anticoagulant/antithrombotic drugs: a review of small-molecule thrombin inhibitors. Eur J Clin Pharmacol. 2002;57:751-758.

41. Giachetti C, Bertolino M, Canali S, et al. Pharmacokinetic study in dogs and monkeys after single intravenous and oral administrations of [14C]-ITF-296. Eur J Drug Metab Pharmacokinet. 1998;23: 239-250.

42. Monzani MV, Coltro G, Sala A, et al. Pharmacokinetics of ITF 296 (Sinitrodil) a novel organic nitrate, in healthy volunteers. Eur J Pharm Sci. 1999;7:179-184.

43. Monzani MV, Coltro G, Jiritano L, et al. Pharmacokinetic profile of ITF 296 in rats and dogs. J Cardiovasc Pharmacol. 1995;26 (suppl 4):S67-S71.

44. Sardina M, Love R, Mizrahi J, et al. Safety and pharmacologic activity of a new nitrate ester, ITF 296, after intravenous administration in healthy volunteers. J Cardiovasc Pharmacol. 1995;26 (suppl 4):S72-S79.

45. Mroszczak EJ, Lee FW, Combs D, et al. Ketorolac tromethamine absorption, distribution, metabolism, excretion, and pharmacokinetics in animals and humans. Drug Metab Dispos. 1987;15:618-626.

46. Lave T, Saner A, Coassolo P, et al. Animal pharmacokinetics and interspecies scaling from animals to man of lamifiban, a new platelet aggregation inhibitor. J Pharm Pharmacol. 1996;48:573-577. 47. arrison MP, Moss SR, Featherstone A, et al. The disposition and metabolism of meropenem in laboratory animals and man. $J$ Antimicrob Chemother. 1989;24(suppl A):265-277.

48. Dedrick R, Bischoff KB, Zaharko DS. Interspecies correlation of plasma concentration history of methotrexate (NSC-740). Cancer Chemother Rep. 1970;54:95-101.

49. Belpaire FM, de Smet F, Vynckier LJ, et al. Effect of aging on the pharmacokinetics of atenolol, metoprolol and propranolol in the rat. J Pharmacol Exp Ther. 1990;254:116-122.

50. Murthy SS, Nelson WL, Shen DD, et al. Pharmacokinetic interaction between verapamil and metoprolol in the dog: stereochemical aspects. Drug Metab Dispos. 1991;19:1093-1100.

51. Bortolotti A, Castelli D, Verotta D, et al. Pharmacokinetic and pharmacodynamic modelling of metoprolol in rabbits with liver failure. Eur J Drug Metab Pharmacokinet. 1989;14:145-151.

52. Rane A, Hogstedt S, Lindberg B, et al. Comparison of different clearance estimates for metoprolol in the rhesus monkey. $J$ Pharmacol Exp Ther. 1984;228:774-778.

53. Mandema JW, Tukker E, Danhof M. Pharmacokinetic-pharmacodynamic modelling of the EEG effects of midazolam in individual rats: influence of rate and route of administration. $\mathrm{Br} J$ Pharmacol. 1991;102:663-668.

54. Granvil CP, Yu AM, Elizondo G, et al. Expression of the human CYP3A4 gene in the small intestine of transgenic mice: in vitro metabolism and pharmacokinetics of midazolam. Drug Metab Dispos. 2003;31:548-558.
55. Kuroha M, Azumano A, Kuze Y, et al. Effect of multiple dosing of ketoconazole on pharmacokinetics of midazolam, a cytochrome P-450 3A substrate in beagle dogs. Drug Metab Dispos. 2002;30:63-68.

56. Garzone PD, Kroboth PD. Pharmacokinetics of the newer benzodiazepines. Clin Pharmacokinet. 1989;16:337-364.

57. Higuchi S, Shiobara Y. Comparative pharmacokinetics of nicardipine hydrochloride, a new vasodilator, in various species. Xenobiotica. 1980;10:447-454.

58. Kawakami J, Yamamoto K, Sawada Y, et al. Prediction of brain delivery of ofloxacin, a new quinolone, in the human from animal data. J Pharmacokinet Biopharm. 1994;22:207-227.

59. Scatina JA, Hicks DR, Kraml M, et al. Metabolic disposition and pharmacokinetics of pelrinone, a new cardiotonic drug, in laboratory animals and man. Eur J Drug Metab Pharmacokinet. 1990;15:37-48.

60. Owens SM, Hardwick WC, Blackall D. Phencyclidine pharmacokinetic scaling among species. J Pharmacol Exp Ther. 1987;242:96-101. 61. Boxenbaum H. Interspecies variation in liver weight, hepatic blood flow, and antipyrine intrinsic clearance: extrapolation of data to benzodiazepines and phenytoin. J Pharmacokinet Biopharm. 1980;8:165-176.

62. Evans GH, Nies AS, Shand DG. The disposition of propranolol, 3: decreased half-life and volume of distribution as a result of plasma binding in man, monkey, dog and rat. J Pharmacol Exp Ther. 1973;186:114-122.

63. Guentert TW, Huang JD, Oie S. Disposition of quinidine in the rabbit. J Pharm Sci. 1982;71:812-815.

64. Iven $\mathrm{H}$. The pharmacokinetics and organ distribution of ajmaline and quindine in the mouse. Naunyn Schmiedebergs Arch Pharmacol. 1977;298:43-50.

65. Ueda CT, Ballard B, Rowland M. Concentration-time effects of quinidine disposition kinetics in rhesus monkeys. J Pharmacol Exp Ther. 1977;200:459-468.

66. Walker DK, Ackland MJ, James GC, et al. Pharmacokinetics and metabolism of sildenafil in mouse, rat, rabbit, dog and man. Xenobiotica. 1999;29:297-310.

67. Rana KZ, Dudley MN. Clinical pharmacokinetics of stavudine. Clin Pharmacokinet. 1997;33:276-284.

68. Kaul S, Dandekar KA, Schilling BE, et al. Toxicokinetics of 2',3'-didehydro-3'-deoxythymidine, stavudine (D4T). Drug Metab Dispos. 1999;27:1-12.

69. Cruze CA, Kelm GR, Meredith MP. Interspecies scaling of tebufelone pharmacokinetic data and application to preclinical toxicology. Pharm Res. 1995;12:895-901.

70. Gascon AR, Calvo B, Hernandez RM, et al. Interspecies scaling of cimetidine-theophylline pharmacokinetic interaction: interspecies scaling in pharmacokinetic interactions. Pharm Res. 1994;11:945-950.

71. Tanaka E, Ishikawa A, Horie T. In vivo and in vitro trimethadione oxidation activity of the liver from various animal species including mouse, hamster, rat, rabbit, dog, monkey and human. Hum Exp Toxicol. 1999;18:12-16.

72. Loscher W. Serum protein binding and pharmacokinetics of valproate in man, dog, rat and mouse. J Pharmacol Exp Ther. 1978;204:255-261.

73. Lave T, Dupin S, Schmitt C, et al. Integration of in vitro data into allometric scaling to predict hepatic metabolic clearance in man: application to 10 extensively metabolized drugs. J Pharm Sci. 1997;86:584-590. 